\title{
Exploring the Implementation of Individual Care Plans in Relation to Characteristics of Staff
}

\author{
Anna Condelius', Ulf Jakobsson², Staffan Karlsson ${ }^{3,4}$ \\ ${ }^{1}$ Department of Health Sciences, Faculty of Medicine, Lund University, Lund, Sweden \\ ${ }^{2}$ Centre for Primary Health Care Research, Faculty of Medicine, Lund University, Malmö, Sweden \\ ${ }^{3}$ Department of Health Sciences, Faculty of Medicine, Lund University, Lund, Sweden \\ ${ }^{4}$ School of Health and Welfare, Halmstad University, Halmstad, Sweden \\ Email: anna.condelius@med.lu.se,ulf.jakobsson@med.lu.se, staffan.karlsson@med.lu.se, \\ staffan.karlsson@hh.se
}

Received 28 July 2016; accepted 21 August 2016; published 24 August 2016

Copyright (C) 2016 by authors and Scientific Research Publishing Inc.

This work is licensed under the Creative Commons Attribution International License (CC BY). http://creativecommons.org/licenses/by/4.0/

c) (i) Open Access

\begin{abstract}
The aim was to explore the implementation of individual care plans in municipal elderly care in relation to characteristics of staff. Data regarding characteristics of staff were derived through a questionnaire distributed to all staff working in the care for older people, $(\mathrm{N}=908, n=245)$ in four municipalities in Sweden. The number of care plans established during a one-year period was collected through a contact person in each municipality. In total 47 individual care plans were established during the study year. Significantly more staff in the municipality that had the most number of established individual care plans agreed that there had been sufficient education $(p=$ 0.017), sufficient time $(p=0.002)$ and routines established regarding individual care plans $(p=$ $0.014)$ and had a significantly better job satisfaction $(p=0.001)$, compared to staff in the other municipalities. Implementation leaders may need to take the working conditions and the perception of available resources among staff into consideration in the on-going process of implementing individual care plans.
\end{abstract}

Keywords

Aged/Aged 80 and Over, Patient Care Planning, Health Plan Implementation

\section{Introduction}

In Sweden, as in other countries, lack of coordination and cooperation between various providers of care poses 
problems in terms of continuity and quality of care, in particular among older people with more complex care needs. To find a remedy for this problem in Sweden, a new paragraph was inaugurated in the Health and Medical Services Act [1] and in the Social Services Act [2] in January 2010. The paragraph makes clear that the county councils and the municipalities shall collaborate and establish an individual care plan (ICP) for persons in need of both social services and healthcare. A successful implementation and use of ICP may contribute to improved inter-professional collaboration and better continuity in care for older people. However, to transform a policy into action is rarely a straightforward process and the attitudes and behaviour among frontline staff should not be underestimated [3]. To fully understand organisational change, it is necessary to understand changes among the individuals involved [4]. Thus, the influence of staff on the process of implementing ICP in elderly care needs further exploration.

\section{Theoretical Framework}

The Consolidated Framework for Implementation Research (CFIR) [5] provides an overarching typology for implementation research and has been used as guidance in the design of this study. The framework was developed through a review of published theories about constructs that influence implementation. The framework is composed of five overarching domains; of which two are analysed in this study, i.e. "Process" and "Characteristics of individuals". The domain "Process" may be evaluated by the actual execution i.e. the actual use and spread of the intervention in the organisation [5], in this case the use of ICP.

The domain "Characteristics of individuals" [5] emphasises that organisational change and the implementation of new routines is influenced by the individuals involved. Two constructs in this domain are analysed in this study and are classified as "Knowledge and beliefs" and "Individuals' identification with organisation" [5]. The construct "Knowledge and beliefs" refers to the individuals' knowledge, thought and opinions about the intervention. The actual use of ICP among professionals (the outcome, execution) can be regarded as a human behaviour. As such it may be predicted by the perceived usefulness and ease of use among the intended users [6]. $\mathrm{Yu}, \mathrm{Li}$ and Gagnos [7] performed a study about the acceptance of Health IT in long-term care facilities and found a significant relation between perceived usefulness, perceived ease of use and the intention to use Health IT among the caregivers. Thus, it may be hypothesised that the acceptance of ICP among staff as a useful and valuable tool in the collaboration with professionals in other organisations and in the care of older people may impact their behaviour in using it. However, their use of ICP may also be related to their belief that they have access to the appropriate skills, resources and support [6]. Since ICP is regulated by law it can be regarded as an externally developed intervention not originating from those who are expected to use it. This puts demand on a well performed dissemination process [8] where staff receives the education, information and resources they need to use ICP in daily practise. Fernandes [9] conducted a study about the process of implementing advanced care plans in aged care facilities. The results showed that the provision of education to staff enhanced their knowledge to take part in advanced care planning and that a more formalised procedure for data collection and documentation improved the number, as well as the quality of the plans that were established. Thus, the acceptance of ICP among staff and their perception of organisational support in terms of education and availability of resources may influence the actual spread and use of ICP. However, this relationship has not been investigated and needs further exploration.

The construct "Individuals' identification with organisation" [5] emphasise that the relationship the individuals have to the organisation they work in may affect their attitudes regarding using an intervention and thus their willingness to engage in a changing process. An increased workload has been reported among staff in elderly care with stress, fatigue and job strain common problems cited by employees in these organisations [10] [11]. Emotional exhaustion has been shown to impact work attitudes and job performance among staff [12] and low job-satisfaction has been shown to be related to the intention to leave the elderly care work sector [13]. Considering that successful implementation is greatly influenced by the engagement among the individuals involved [14], job satisfaction among staff can be expected to influence the process of change and the use of ICP. However, so far this relationship has not been explored, particularly not in relation to the implementation of ICP in elderly care.

The aim of this study was to explore the implementation of individual care plans in municipal elderly care in relation to characteristics of staff. 


\section{Method}

\subsection{Sample}

The study was conducted in four municipalities in southern Sweden. All staff working in nursing homes, or with home nursing care for older people, were included $(\mathrm{N}=908)$. All working places were operated by the municipalities except for three nursing homes and one staff group providing home-help services to older people that were operated by private agencies.

\subsection{Data and Data Collection}

\subsubsection{Process}

The concept "Process" was operationalised through the actual use of individual care plans and thus the number of established individual care plans in each municipality in collaboration with the county council was collected during a one-year period (November 2013 through December 2014). This was done through a form filled in by contact persons in the municipalities and the private agencies. The form was filled in continuously by the contact persons regarding the date and the organisations involved in the establishment of each individual care plan.

\subsubsection{Characteristics of Staff}

Data regarding "Characteristics of individuals/staff" was derived through a questionnaire and distributed to staff at baseline in November 2013. The questionnaires were distributed by a contact person at each working place and were returned to the research group in preaddressed envelopes after they were completed. The contact persons were also responsible for reminding the staff to fill in and return the questionnaire. Thus, the research group did not know the names of those who received the questionnaires and was not in control of how and when staff was reminded. This procedure made the respondents anonymous to the research group. The respondent gave their consent to participate in the study by ticking in a box in the questionnaire and by returning the completed questionnaire. The questionnaire took approximately 30 minutes to complete.

The construct "Knowledge and beliefs about the intervention" was operationalised through seven statements constructed for this study. The statements were intended to capture the subjective opinions and beliefs among staff regarding access to resources and support in terms of own knowledge and received education (statement 1 2), presence of routines and time (statement 3 - 4) and their overall acceptance of ICP as an effective and useful tool (statement 5 - 7). The statements were scored on a four-point scale ranging from $1=$ disagree completely to 4 = agree completely.

The construct of "Individual identification with organisation" was operationalised through The Psychosocial Aspects of Job Satisfaction questionnaire [13]. The questionnaire contains 49 questions measuring eight factors (4 - 11 questions/factor); Workload, Criticism, Cooperation, Expectations and demands, Personal development, Internal motivation, External motivation and Position in the group. The questions are scored on a five-point scale ranging from $0=$ never to $4=$ very often. Total scores are transformed to $0-100$ for each factor by summarising and dividing raw scores by the highest possible score in each factor and multiplied by 100 . This makes it possible to compare factor scores even if they contain various numbers of items [13]. Higher scores indicate a more desirable state. The psychometric properties of the instrument have been shown to be acceptable [13].

\subsection{Data Analyses}

To explore variation in the process of implementing ICP in relation to characteristics of staff the sample was divided into two groups. The division was based on the variation in the process outcome i.e. the number of established ICP in the municipalities during the study year. The municipality that had the most number of established ICP (municipality I) was compared to those that had fewer and more similar number of established plans (municipalities II-V) regarding the beliefs about individual care plans and job satisfaction among staff. Comparisons were performed using Mann-Whitney U-test for ordinal data and Student's t-test for numeric data. A p-value below 0.05 was regarded as significant.

A total of 46 out of 49 items in the Satisfaction with Work Questionnaire had less than $5 \%$ missing values. The question "cooperation with colleagues" had 5.7\% missing values and the question "cooperation with staff in other units" had $7.8 \%$ missing values. These missing values were replaced with the median value of the group (i.e. municipality with most individual care plans and municipalities with fewer). The items with more missing 
values were: “criticism from subordinates” (33.3\%) and "praise from subordinates” (33.9\%). Due to the high number of missing values these two questions were excluded in the calculation of total scores for the factors they belonged to, i.e. Criticism or Position in the group, and in the calculation of total score for job satisfaction.

The Regional Ethical Review Board in Lund approved the study (Dnr 2013/549).

\section{Results}

In total 245 staff returned the questionnaire giving an overall response rate of $26.9 \%$. Fifty-two persons declined participation by returning a form stating that they didn't want to participate. The reasons given for not wanting to participate were not having the time $(n=8)$, newly employed $(n=2)$, not interested $(n=4)$ and not relevant questions $(n=1)$. A total of $76.3 \%$ of the respondents were assistant or auxiliary nurses, $13.1 \%$ were registered nurses, $5.7 \%$ were occupational therapists and $4.1 \%$ were physiotherapists. Five percent of the respondents had nine-year compulsory school education, $62 \%$ had upper secondary school education and $32 \%$ had university education. Ninety-five percent were women and the mean time working at the present working site were 10 years (range 0 - 38 years). There were no significant differences between the four municipalities regarding the proportion of each profession that responded to the questionnaire.

\subsection{Process}

In total 47 individual care plans were established in the four municipalities during the study period. Of these, 31 were established in municipality I, three in municipality II, seven in municipality III and six in municipality IV (Table 1). A total of 39 were established in collaboration with primary healthcare and eight in collaboration with specialised hospital care.

\subsection{Characteristics of Staff in Relation to Process}

Overall it was found high agreement and no significant differences between groups in the statements regarding knowledge about which information that should be written in a individual care plan (90.2\% stating partly agree or agree completely); that an individual care plan is an effective tool to provide high quality care and service (91.9\%); that an individual care plan is useful in collaboration with professionals in other organisations (90.1\%) and that there should be more individual care plans established than at present (65.5\%) (Table 2). A significantly larger proportion of staff in the municipality that had the most number of established individual care plans agreed that there had been a satisfactory amount of education about how to establish individual care plans (80.4\% vs $63.8 \%)$, that there is sufficient time to establish them (58.9\% vs $39.1 \%)$ and that there are routines in the organisation about how to establish the plans ( $73.2 \%$ vs $67.8 \%)$.

Overall the staff rated the highest value for internal motivation (mean 78.7) and the lowest for external motivation (mean 47.3) (Table 3). Staff working in the municipality that had the most number of established plans had a significantly higher (better) mean value compared to staff in the other municipalities regarding personal development (mean 71.1 vs 65.9), workload (mean 63.8 vs 56.5), expectations and demands (mean 65.7 vs 61.1), cooperation (mean 76.9 vs 70.1 ), position in the group (mean 66.4 vs 61.3) and total job satisfaction (mean 67.8 vs 62.5). There were no significant differences in the factors: criticism, internal motivation or external motivation.

Table 1. Inhabitants, number of established Individual Care Plans (ICP) and the number of respondents in the four municipalities.

\begin{tabular}{cccc}
\hline & Inhabitants & Established ICP & Staff \\
n/\% aged 65+ & N/n respondents \\
Municipality I & $20248 / 17.3$ & 31 & $250 / 73$ \\
$\begin{array}{c}\text { Municipality II } \\
\text { (including one private nursing home) } \\
\text { Municipality III }\end{array}$ & $17211 / 17.9$ & 3 & $283 / 72$ \\
$\begin{array}{c}\text { (including one private provider of social } \\
\text { care and two private nursing homes) } \\
\text { Municipality IV }\end{array}$ & 22 994/18.9 & 7 & $181 / 37$ \\
\hline
\end{tabular}


Table 2. Beliefs about Individual Care Plans (ICP) among staff in the total sample and comparisons of the municipality with the most established ICP and those with fewer.

\begin{tabular}{|c|c|c|c|c|}
\hline & $\begin{array}{l}\text { Total sample } \\
\mathrm{n}=245\end{array}$ & $\begin{array}{l}\text { Municipality I } \\
\mathrm{n}=73\end{array}$ & $\begin{array}{l}\text { Other municipalities } \\
\text { (II-IV) } n=172\end{array}$ & p-value* \\
\hline $\begin{array}{l}\text { It is clear to me which information that should be written in an } \\
\text { ICP }(\%)(n=174)\end{array}$ & & & & 0.154 \\
\hline Disagree completely & 2.9 & 0 & 4.2 & \\
\hline Partly disagree & 6.9 & 3.6 & 8.5 & \\
\hline Partly agree & 47.1 & 44.6 & 48.3 & \\
\hline Agree completely & 43.1 & 51.8 & 39.0 & \\
\hline $\begin{array}{l}\text { There has been a satisfactory amount of education about how to } \\
\text { establish ICP }(\%)(n=172)\end{array}$ & & & & 0.017 \\
\hline Disagree completely & 9.9 & 0 & 14.7 & \\
\hline Partly disagree & 20.9 & 19.6 & 21.6 & \\
\hline Partly agree & 47.1 & 51.8 & 44.8 & \\
\hline Agree completely & 22.1 & 28.6 & 19.0 & \\
\hline There is sufficient time to establish ICP $(\%)(n=171)$ & & & & 0.002 \\
\hline Disagree completely & 12.3 & 0 & 18.3 & \\
\hline Partly disagree & 42.1 & 41.1 & 42.6 & \\
\hline Partly agree & 36.8 & 44.6 & 33.0 & \\
\hline Agree completely & 8.8 & 14.3 & 6.1 & \\
\hline $\begin{array}{l}\text { There are routines in the organisation about how to establish ICP } \\
(\%)(n=174)\end{array}$ & & & & 0.014 \\
\hline Disagree completely & 7.5 & 0 & 11.0 & \\
\hline Partly disagree & 23.0 & 26.8 & 21.2 & \\
\hline Partly agree & 45.4 & 39.3 & 48.3 & \\
\hline Agree completely & 24.1 & 33.9 & 19.5 & \\
\hline $\begin{array}{l}\text { ICP is an effective tool to provide high quality care and services } \\
(\%)(\mathrm{n}=174)\end{array}$ & & & & 0.668 \\
\hline Disagree completely & 1.1 & 0 & 1.7 & \\
\hline Partly disagree & 6.9 & 5.4 & 7.6 & \\
\hline Partly agree & 42.5 & 41.1 & 43.2 & \\
\hline Agree completely & 49.4 & 53.6 & 47.5 & \\
\hline $\begin{array}{l}\text { ICP is useful in collaboration with professionals in other } \\
\text { organisations }(\%)(n=172)\end{array}$ & & & & 0.106 \\
\hline Disagree completely & 1.7 & 0 & 2.6 & \\
\hline Partly disagree & 8.1 & 5.3 & 9.6 & \\
\hline Partly agree & 45.9 & 38.6 & 49.6 & \\
\hline Agree completely & 44.2 & 56.1 & 38.3 & \\
\hline $\begin{array}{l}\text { There should be more ICP established than at present (\%) } \\
(\mathrm{n}=170)\end{array}$ & & & & 0.768 \\
\hline Disagree completely & 12.4 & 8.9 & 14.0 & \\
\hline Partly disagree & 22.4 & 25.0 & 21.1 & \\
\hline Partly agree & 36.5 & 35.7 & 36.8 & \\
\hline Agree completely & 28.8 & 30.4 & 28.1 & \\
\hline
\end{tabular}

*Mann-Whitney U-Test. 
Table 3. Psychosocial aspects of job-satisfaction in the total sample and comparison between the municipality that had the most established ICP and those with fewer.

\begin{tabular}{|c|c|c|c|c|}
\hline Factor & $\begin{array}{l}\text { Total sample } \\
\text { Mean (SD) }\end{array}$ & $\begin{array}{l}\text { Municipality I } \\
\text { Mean (SD) }\end{array}$ & $\begin{array}{l}\text { Other municipalities } \\
\text { (II-IV) Mean (SD) }\end{array}$ & p-value* \\
\hline Personal development $(\mathrm{n}=231)$ & $67.5(17.6)$ & $71.1(16.1)$ & $65.9(18.0)$ & 0.039 \\
\hline Workload $(n=233)$ & $58.7(16.1)$ & $63.8(12.4)$ & $56.5(16.9)$ & 0.001 \\
\hline Criticism $(n=232)$ & $68.2(14.5)$ & $67.8(14.1)$ & $68.4(14.7)$ & 0.076 \\
\hline Expectations and demands $(\mathrm{n}=239)$ & $65.7(12.2)$ & $65.7(14.1)$ & $61.6(16.5)$ & 0.033 \\
\hline Cooperation $(n=228)$ & $72.2(15.2)$ & $76.9(11.0)$ & $70.1(16.3)$ & 0.001 \\
\hline Internal motivation $(\mathrm{n}=238)$ & $78.7(14.6)$ & $79.6(14.6)$ & $78.3(14.1)$ & 0.514 \\
\hline External motivation $(\mathrm{n}=234)$ & $47.3(18.0)$ & $50.0(15.2)$ & $46.1(19.1)$ & 0.104 \\
\hline Position in the group $(\mathrm{n}=238)$ & $62.9(15.2)$ & $66.4(12.6)$ & $61.3(16.0)$ & 0.010 \\
\hline Total job satisfaction $(\mathrm{n}=212)$ & $64.2(11.9)$ & 67.8 (8.9) & $62.5(12.7)$ & 0.001 \\
\hline
\end{tabular}

*Student's t-test.

\section{Discussion}

The process of implementing ICP in municipal elderly care appears to be slow and varies between municipalities. Despite that ICP has been regulated since 2010. The results show a rather great disparity in the number of plans established, with one municipality having 31 and the other 3 - 7 (Table 1). According to the regulations an individual care plan should be established when a person has a need for both social services and healthcare, which means the majority of the elderly people who receive social services in the municipalities. Research has shown that $75 \%$ of elderly people who receive social services also have contact with outpatient care and $58 \%$ have contact with specialist care [15]. Thus, one could expect a higher number of established plans than demonstrated in the result. The problem, however, is that the regulation also states; "The plan shall be established if the municipality or the county council determines that it is necessary for the individual to get their needs met” [1] [2]. This wording leaves it open for interpretation regarding when an ICP should be established. Thus, the organisations that intend to implement the legislation are also expected to formulate the policy, i.e. they are policy makers and policy implementers at the same time [16]. The advantage of this is that the intervention or the policy can be adapted to fit the organisation and thus be easier to implement [14]. The management has a key role in the interpretation and the development of a clear policy adapted to each organisation. However, the problem is that there is a risk for disagreements regarding how to define the targeted population between the numerous organisations and providers involved in the establishment of ICP. Furthermore, it becomes difficult to evaluate the accuracy in the demonstrated number of established plans. The variation in the number of established ICP in this study might partly be explained by this problem. This has, however, not been investigated in this study and thus needs further exploration.

In general, staff within elderly care seemed to have positive attitudes about ICP with the majority in agreement that it was clear what information should be written in an care plan; the establishment of ICP is a useful document in the collaboration with other care providers; an individual care plan is an efficient tool in providing good quality in care and that they should be established more often (Table 2). These findings are encouraging since an acceptance of the intervention among staff increases motivation and the chances of successful implementation and use of an intervention. However, the variations in the process outcome i.e. the use of ICP between municipalities seems not to be explained by beliefs about the plans among staff, since there were no significant differences in the questions between the municipality that had the most established care plans and those with the fewest. The variation in the process seems rather to be influenced by differences in their perception of availability of resources i.e. the education of staff, staff time and the establishment of routines. The municipality that had the most established care plans had a significantly larger proportion of staff stating that there had been sufficient education and that there was a sufficient amount of time and routines regarding how to establish ICP (Table 2). This result is in line with previous research showing that organisational investments in terms of education [9] [17], time and staff [18] [19] are important in the implementation processes and cannot be ignored. However, the results in this study indicate that it might be necessary for managers and implementation leaders to pay at- 
tention to the opinion about these investments among staff and not only to the investments per se. This knowledge is of value for future research as well as for managers involved in the ongoing process of implementing ICP in Sweden. However, due to the low response rate these findings should be interpreted with caution and more research is needed to confirm these results.

The construct in the theoretical framework referred to as “Individuals' identification with organisation" seems to influence the implementation of individual care plans in municipal elderly care. The municipality that had the most established care plans had a significantly higher degree of general job satisfaction among staff and a higher mean value in six out of nine factors compared to the other municipalities (Table 3). According to the constructors a mean value above 75 is desirable [13] and this was found in the total sample in the factor "Internal motivation" and in the municipality that had the most established care plans in the factor "cooperation". The mean values shown in this study do not differ from previous studies about job satisfaction among staff within elderly care [20] [21]. Previous studies have found that the caring climate, working environment and the leadership all have an impact on job satisfaction [21] [22]. Consequently, interventions improving the caring, working climate and leadership may have a positive impact on job-satisfaction and also the process of implementing individual care plans.

\section{Methodological Consideration}

There are methodological issues that need to be addressed. The study does not include the characteristics of managers or staff working in the county council and thus does not cover all those involved in the process of implementing ICP in the care of older people. This limits the generalisations of the results and the conclusions that can be made regarding the influence of staff during the implementation process. The low response rate also constitutes a threat to the external validity in this study and limits the conclusions that can be made from the results. The low response rate may be explained by the facts that contact persons and not members of the research group were used to distribute the questionnaires and to inform and remind the staff about the study. For an increased control, the research group could have distributed the reminder to fill in the questionnaires to the staff. The low response rate may also be explained by the high workload and the lack of time among staff indicated in the results. Having more time available for responding to the questionnaire might have solved this problem. This has implications for future studies where questionnaires are used for data collections among staff working under pressure. However, despite the low response rate this study adds with valuable knowledge about a process that has not been explored previously, that is ongoing and involves large parts of the health-and social care sector in Sweden. Thus, the results are of significance for future research about this process as well as for policymakers and managers with responsibility for implementing ICP who might need to take the working conditions as well as the attitudes among staff into consideration.

A high degree of missing values were found in the items "criticism from subordinates" (33.3\%) and "praise from subordinates” (33.9\%) in the instrument Job Satisfaction Questionnaire, as were found in another study [23]. This could be due to the many items of the instrument but it is more likely that these questions were not applicable in this sample. The sample was comprised mostly of frontline staff, assistant or auxiliary nurses (76.3\%), without any subordinates. For further research within this context it is suggested to take out these questions and further develop the instrument.

The Consolidated Framework for Implementation Research (CFIR) [5] provided this study with a pragmatic structure for organising the results and their influence on implementation of individual care plans in elderly care. The CFIR was shown to be useful and can serve as a guide to explore factors that influence the implementation of care plans. Such a framework promotes comparisons of the results with other contexts and studies over time.

\section{Conclusion}

The implementation of individual care plans remains a slow process with disparities between municipalities. Since it is up to each authority to determine when it is appropriate to establish an individual care plan, it is impossible to evaluate whether the established number of care plans is appropriate or not. In general, staff within elderly care seems to have a positive attitude towards individual care plans. The variation in the process of implementing the plans in municipal elderly care seems to be influenced by the perception of available resources and job satisfaction among staff. This study is explorative and the low response rate limits the conclusions that can be made. However, the results indicate that the working conditions and the prerequisite to establish ICP 
among staff need to be taken into consideration in research and in the ongoing process of implementing ICP in municipal elderly care. Since ICP is regulated by law and a successful implementation may contribute to improved continuity and quality in care, this process is of great importance and needs further investigation.

\section{Acknowledgements}

We are grateful to all the staff who participated in the study, to the contact persons in the municipalities and to Denis Selan for their help with data collection. We also want to thank Patrick Reilly for revising the language. We are grateful to the Swedish Institute for Health Sciences (Vårdalinsitutet) for financial support.

\section{References}

[1] Ministry of Health and Social Affairs Sweden (1982) The Swedish Health and Medical Services Act, 763.

[2] Ministry of Health and Social Affairs Sweden (2001) Social Services Act, 453.

[3] Hill, M. and Hupe, P. (2009) Implementing Public Policy. 2nd Edition, SAGE Publications Inc., Thousand Oaks.

[4] Davis, R., Campbell, R., Hildon, Z., Hobbs, L. and Michie, S. (2014) Theories of Behaviour and Behaviour Change across the Social and Behavioural Sciences: A Scoping Review. Health Psychology Review, 9, 323-344.

[5] Damschroder, L.J., Aron, D.C., Keith, R.E., Kirsh, S.R., et al. (2009) Fostering Implementation of Health Services Research Findings into Practice: A Consolidated Framework for Advancing Implementation Science. Implementation Science, 4, 50. http://dx.doi.org/10.1186/1748-5908-4-50

[6] Mathieson, K. (1991) Predicting User Intentions: Comparing the Technology Acceptance Model with the Theory of Planned Behavior. Information Systems Research, 2, 173-191. http://dx.doi.org/10.1287/isre.2.3.173

[7] Yu, P., Li, H. and Gagnon, M.P. (2009) Health IT Acceptance Factors in Long-Term Care Facilities: A Cross-Sectional Survey. International Journal of Medical Informatics, 78, 219-229. http://dx.doi.org/10.1016/j.ijmedinf.2008.07.006

[8] Dobbins, M., Ciliska, D., Cockerill, R., Barnsley, J. and DiCenso, A. (2002) A Framework for the Dissemination and Utilization of Research for Health-Care Policy and Practice. The Online Journal of Knowledge Synthesis for Nursing, 9, 7.

[9] Fernandes, G. (2008) Implementation of Best Practice in Advance Care Planning in an "Ageing in Place” Aged Care Facility. International Journal of Evidence-Based Healthcare, 6, 270-276.

[10] Brulin, C., Winkvist, A. and Langendoen, S. (2000) Stress from Working Conditions among Home Care Personnel with musculoskeletal Symptoms. Journal of Advanced Nursing, 31, 181-189. http://dx.doi.org/10.1046/j.1365-2648.2000.01209.x

[11] Orrung-Wallin, A., Jakobsson, U. and Edberg, A.K. (2013) Job Strain and Stress of Conscience among Nurse Assistants Working in Residential Care. Journal of Nursing Management, 23, 368-379.

[12] Cropanzano, R., Rupp, D.E. and Byrne, Z.S. (2003) The Relationship of Emotional Exhaustion to Work Attitudes, Job Performance, and Organizational Citizenship Behaviors. Journal of Applied Psychology, 88, 160-169. http://dx.doi.org/10.1037/0021-9010.88.1.160

[13] Engström, M., Ljunggren, B., Lindqvist, R. and Carlsson, M. (2006) Staff Satisfaction with Work, Perceived Quality of Care and Stress in Elderly Care: Psychometric Assessments and Associations. Journal of Nursing Management, 14, 318-328. http://dx.doi.org/10.1111/j.1365-2934.2006.00625.x

[14] Greenhalgh, T., Robert, G., Macfarlane, F., Bate, P. and Kyriakidou, O. (2004) Diffusion of Innovations in Service Organizations: Systematic Review and Recommendations. Milbank Quarterly, 82, 581-629. http://dx.doi.org/10.1111/j.0887-378X.2004.00325.x

[15] Karlsson, S., Edberg, A.K., Westergren, A., Hallberg, I.R. (2008) Older People Receiving Public Long-Term Care in Relation to Consumption of Medical Health Care and Informal Care. The Open Geriatric Medicine Journal, 1, 1-9. http://dx.doi.org/10.2174/1874827900801010001

[16] Johansson, S. (2010) Implementing Evidence-Based Practices and Programmes in the Human Services: Lessons from Research in Public Administration. European Journal of Social Work, 13, 109-125. http://dx.doi.org/10.1080/13691450903135691

[17] Savvas, S., Toye, C., Beattie, E. and Gibson, S.J. (2014) Implementation of Sustainable Evidence-Based Practice for the Assessment and Management of Pain in Residential Aged Care Facilities. Pain Management Nursing, 15, 819-825. http://dx.doi.org/10.1016/j.pmn.2013.09.002

[18] Ellen, M.E., Leon, G., Bouchard, G., Ouimet, M., et al. (2014) Barriers, Facilitators and Views about Next Steps to Implementing Supports for Evidence-Informed Decision-Making in Health Systems: A Qualitative Study. Implementa- 
tion Science, 9, 179. http://dx.doi.org/10.1186/s13012-014-0179-8

[19] Hagedorn, H.J., Stetler, C.B., Bangerter, A., Noorbaloochi, S., et al. (2014) An Implementation-Focused Process Evaluation of an Incentive Intervention Effectiveness Trial in Substance Use Disorders Clinics at two Veterans Health Administration Medical Centers. Addiction Science \& Clinical Practice, 9, 12. http://dx.doi.org/10.1186/1940-0640-9-12

[20] Engström, M., Skytt, B. and Nilsson, A. (2011) Working Life and Stress Symptoms among Caregivers in Elderly Care with Formal and No Formal Competence. Journal of Nursing Management, 19, 732-741. http://dx.doi.org/10.1111/j.1365-2834.2011.01270.x

[21] Orrung-Wallin, A., Jakobsson, U. and Edberg, A.K. (2012) Job Satisfaction and Associated Variables among Nurse Assistants Working in Residental Care. International Psychogeriatrics, 24, 1904-1918. http://dx.doi.org/10.1017/S1041610212001159

[22] Hasson, H. and Arnetz, J.E. (2008) Nursing Staff Competence, Work Strain, Stress and Satisfaction in Elderly Care: A Comparison of Home-Based Care and Nursing Homes. Journal of Clinical Nursing, 17, 468-481.

[23] Orrung-Wallin, A., Edberg, A.K., Beck, I. and Jakobsson, U. (2013) Psychometric Properties Concerning Four Instruments Measuring Job Satisfaction, Strain, and Stress of Conscience in a Residential Care Context. Archives of Gerontology and Geriatrics, 57, 162-171. http://dx.doi.org/10.1016/j.archger.2013.04.001

\section{Submit or recommend next manuscript to SCIRP and we will provide best service for you:}

Accepting pre-submission inquiries through Email, Facebook, LinkedIn, Twitter, etc. A wide selection of journals (inclusive of 9 subjects, more than 200 journals)

Providing 24-hour high-quality service

User-friendly online submission system

Fair and swift peer-review system

Efficient typesetting and proofreading procedure

Display of the result of downloads and visits, as well as the number of cited articles

Maximum dissemination of your research work

Submit your manuscript at: http://papersubmission.scirp.org/ 